\title{
A IDENTIDADE CAPIXABA EM QUESTÃO: UMA ANÁLISE PSICOSSOCIAL
}

\author{
Aldemir Luiz Garcia \\ Centro de Ensino Superior Anísio Teixeira (CESAT) e \\ Centro Universitário de Vila Velha (UVV).
}

RESUMO:Buscou-se o desenvolvimento de um estudo abarcando as representações sociais de professores sobre o folclore, verificando-se as conexões destas com a construção da identidade social. A pesquisa abarcou 32 docentes do ensino fundamental da rede pública municipal de Vitória. A coleta de dados realizou-se por meio de um questionário semi-estruturado que versou sobre temas relativos à problemática folclore capixaba e identidade. As questões estruturadas tiveram suas respostas tabuladas com o intuito de fornecerem dados quantitativos, já as respostas livres foram organizadas tendo em vista a construção de um corpus representacional que permitisse a aplicação de uma análise temática de conteúdo. Os resultados indicaram que os sujeitos associam o folclore à cultura espontânea e o caracterizam como o principal indicador de uma identidade social local (capixaba), que se constrói por meio da comunicação social, cotidianamente e constitui-se das tradições culturais em geral, tanto materiais quanto imateriais.

PALAVRAS-CHAVE: Psicologia Social; Identidade (Psicologia); Espírito Santo (Estado) - Cultura Popular; Folclore.

\section{THE CAPIXABA'S IDENTITY IN QUESTION: A PSYCHOSOCIAL STUDY.}

ABSTRACT: Searched the development of a study on the social representations of teachers about the folklore, verifying the connections of these with the construction of the social identity. The research comprise 32 teachers of the basic education of the public municipal net of Vitoria The collection of data was carried through by a half-structuralized questionnaire that turned on the problematic of folklore and identity. The structuralized questions had its answers tabulated with intention to supply quantitative information, already the free answers had been organized in view of the construction of a corpus that allowed the application of a thematic analysis of content. The results had indicated that teachers associate the folklore to the spontaneous culture and they characterize it as the main pointer of a local social identity (capixaba), that is constructed by means of the social communication, daily, and consists of the cultural traditions in general, material as much as immaterial.

KEY-WORDS: Social Psychology;; Identity (Psychology); Espírito Santo (State) - Popular Culture; Folklore.

\section{INTRODUÇÃO}

O interesse pela temática cultura popular e identidade, liga-se à percepção de que o lugar do indivíduo no mundo passa por investimentos simbólicos - comportamentos, atitudes, opiniões pelos quais ele se afirma e negocia com os demais atores, sua forma de inserção na sociedade. Afinal, a cultura popular, à margem do ensino oficial, vem assegurando a constituição de uma base cultural comum nas diversas sociedades, onde sua sobrevivência é garantida e decerto permanecerá, pela transmissão de geração em geração.

Burity (2002) ressalta que a problemática da cultura é hoje um veio de discussão consagrado, que não apenas retrata uma orientação teórica no campo das ciências sociais, mas também reagrupa as preocupações, classicamente associadas à cultura em torno do tema da identidade. Essa orientação teórica, diz respeito à compreensão de que a vivência social é sempre simbolicamente mediada, seja pelo discurso, seja pelas manifestações artísticas em sentido amplo, de modo que tanto se pode dizer que tal vivência é culturalmente construída, como dizer que a cultura é uma construção social, que interage de forma complexa com os diferentes lugares e práticas onde se situam ou por onde circulam os agentes sociais, dando sentido e direção - ou questionando-os - a seus pertencimentos e ações.

Sob esse prisma, o folclore, entendido como cultura popular, forma de saber e processo intelec- 
tual de criação ou renovação de valores, constituise objeto de investigação científica privilegiado para a Psicologia Social, que, numa perspectiva renovadora - temática, teórica e metodológica - tem buscado considerar tanto os comportamentos individuais, como os fatos sociais em sua concretude e singularidade histórica.

Portanto, tendo em vista a multiplicidade da utilização dessa cultura popular, acreditamos que a escola e seus atores podem e devem servir-se do folclore como excelente meio de transmissão de conhecimentos, ao mesmo tempo em que revelador da cultura do povo. Desta maneira, estaria utilizando esta outra lógica, que não está nos livros ou no conteúdo formal, onde quase sempre encontramos a versão oficial, para conhecer e interagir com as facetas da consciência popular.

Partindo dessas premissas, esta pesquisa focalizou uma análise sobre as representações sociais de professores sobre o folclore, particularmente o folclore capixaba e sua disseminação, procurando estabelecer conexões entre estas representações com a construção da identidade social, à busca de subsídios que indiquem objetivamente a relação dialética entre cultura e identidade.

\section{MÉTODO}

Acreditando poder contribuir com o debate sobre o binômio cultura e identidade, propusemos uma análise psicossocial da questão, a partir de uma investigação sobre as representações sociais de professores do município de Vitória sobre o folclore, com a intenção de verificar suas ligações com a construção de uma identidade social. Para tanto nos apoiamos no conceito de representação social, proposto inicialmente por Moscovici (1978) e no conceito de identidade social, proposto por Tajfel $(1982,1983)$.

A nossa posição partiu da concepção de que a formação de identidades ocorre num processo coletivo envolvendo os vários grupos que compõem uma determinada sociedade com o objetivo de organizar a realidade dos indivíduos criando diferenciações entre o que é familiar, compartilhado pelo grupo, e o que é estranho, ou extra-grupo. Tal fenômeno ocorre através das comunicações interindividuais no dia-a-dia, onde fluem conjuntos de conceitos, afirmações e explicações que constituem as representações sociais, através das quais se procede a interpretação e mesmo a construção das realidades sociais.

Nessa perspectiva observamos que, o folclore, devido à pluralidade de seus elementos e ampla circularidade, apresenta-se como um possível instrumento para o diagnóstico de uma identi- dade social localmente partilhada, e que os professores, pela peculiaridade do seu ofício, são importantes articuladores e difusores dessa cultura.

Pesquisamos no total trinta e dois (32) professores de cinco (05) escolas do ensino fundamental. Em relação à caracterização dos sujeitos, apuramos os seguintes dados: a maioria é do sexo feminino $87,5 \%$ dos entrevistados. Suas idades variam entre 24 e 57 anos, sendo a média etária equivalente a 40,5 anos. Quanto ao estado civil 62,5\% são casados; $18,8 \%$ são solteiros; $15,6 \%$ divorciados e $3,1 \%$ viúvos. Em relação à formação acadêmica, todos se declararam licenciados: $18,8 \%$ formados em História, a mesma porcentagem $(18,8 \%)$ em Letras-Português; 15,5\% em Geografia; 12,5\% em Educação Física; 12,5\% em Educação Artística; 9,4\% em Matemática, o mesmo percentual $(9,4 \%)$ em Biologia e, finalmente 3,1\% em LetrasInglês.

Quanto à questão do tempo de serviço prestado na área do magistério, obtivemos uma média de 16,7 anos, sendo o tempo mínimo de 2 anos e o máximo de 38 anos de serviço. Em relação às séries em que os professores lecionam, 65,7\% trabalham com turmas de $5^{\mathrm{a}}$ à $8^{\mathrm{a}}$ séries, enquanto $34,3 \%$ dão aulas para alunos da $1^{\mathrm{a}}$ à $4^{\mathrm{a}}$ séries. Sobre as disciplinas ministradas, elas obedecem à área na qual o professor possui licenciatura, repetindo então os mesmos percentuais apresentados no parágrafo anterior quando nos referimos à área de formação dos sujeitos.

Os dados foram coletados por meio de questionário semi-estruturado, sendo mantidas sob sigilo quaisquer informações sobre a identidade pessoal dos entrevistados. As questões propostas versaram sobre temas relativos à problemática do folclore capixaba e identidade, tendo como matriz os seguintes temas: a) o folclore e suas características, sua dinâmica e o uso das explicações baseadas em fatos folclóricos, além de sua reprodução na atualidade; b) a relação entre o folclore e a identidade; c) homogeneização de comportamentos e atitudes derivadas do compartilhamento de elementos folclóricos comuns; d) a disseminação do folclore na educação e na sociedade em geral.

As questões objetivas (12) tiveram suas respostas agrupadas e tabuladas com o intuito de nos fornecerem dados quantitativos a respeito do seu respectivo assunto. Já as respostas das questões discursivas (4) foram organizadas tendo em vista a construção de um corpus representacional que permitisse a aplicação de uma análise temática de conteúdo (1979). Buscou-se, portanto, categorizar as informações coletadas, para posterior estruturação de resultados. Para tanto, utilizamos 
o seguinte procedimento para as questões com respostas livres: a) análise das respostas destacando o conteúdo relevante a partir dos temas indicados; b) categorização da temática do conteúdo destacado; c) análise das categorias obtidas.

\section{RESULTADOS E DISCUSSÃO}

$\mathrm{Na}$ análise do material, verificamos uma concordância entre os sujeitos que caracterizaram o folclore capixaba, como um conjunto de manifestações culturais e artísticas oriundos do folclore nacional adaptados à região, que pode ser entendido como um indicador identitário, e associado à cultura espontânea ${ }^{1}$, pois se baseia na popularidade e tradicionalidade e tem como principal função facilitar as soluções usuais, cotidianas, admitidas como respostas aos problemas do dia-a-dia, conduzindo os indivíduos a reapropriação e reorganização do seu meio social.

A partir deste delineamento das representações dos professores destacamos alguns pontos iniciais que mereceram um detalhamento, são eles: a caracterização geral do folclore regional, sua ligação à cultura espontânea, à popularidade e a tradicionalidade, e sua função de facilitador na resolução dos problemas cotidianos.

Em primeiro lugar, serão apresentadas as representações sociais dos professores em relação ao folclore capixaba, suas características e quais são as atividades pertinentes ao folclore brasileiro que mais se destacam na cultura local (Tabelas 1 , 2 e Figura 1).

\section{TABELA 1}

Como os professores caracterizam o folclore capixaba

$\begin{array}{lr}\text { RESPOSTAS } & \% \\ \text { Uma cultura erudita } & 6,3 \\ \text { O principal indicador da identidade cultural } & 37,4 \\ \text { Uma cultura de massa } & 12,6 \\ \text { Uma cultura espontânea } & 37,4 \\ \text { Não responderam } & 6,3 \\ \text { TOTAL } & 100\end{array}$

Como é possível observar a partir da Tabela $1,37,4 \%$ dos entrevistados consideram o folclore como cultura espontânea, ao passo que outros $37,4 \%$ consideram-no o principal indicador da identidade cultural.

É interessante observar que $6,3 \%$ dos professores entrevistados não foram capazes de caracterizar o folclore com base nas respostas oferecidas e também não optaram por descrever uma outra possibilidade de resposta. Coincidentemente, o questionamento sobre as características relacionadas ao folclore também deixou de ser respondido por $6,3 \%$ professores, como é possível observar na
Tabela 2.

Tal situação parece indicar um baixo conhecimento dos subsídios da cultura popular por parte de alguns professores, neste caso, parece-nos pertinente refletir se o valor educativo do folclore realmente tem sido suficientemente aproveitado pela escola, seja dentro do projeto pedagógico, seja no espaço da sala de aula, servindo como base para a construção do conhecimento tanto de professores quanto de alunos.

TABELA 2

Características mais relacionadas ao folclore capixaba segundo os professores

$\begin{array}{lr}\text { RESPOSTAS } & \% \\ \text { Popularidade } & 15,6 \\ \text { Tradicionalidade } & 34,4 \\ \text { Popularidade e Tradicionalidade } & 43,7 \\ \text { Não responderam } & 6,3 \\ \text { TOTAL } & 100\end{array}$

É possível observar ainda na Tabela 2, que a maioria dos professores consideram a tradicionalidade $(34,4 \%)$ e a popularidade $(15,6 \%)$ como as principais características do folclore, sendo que $43,7 \%$ deles associaram ambas as opções.

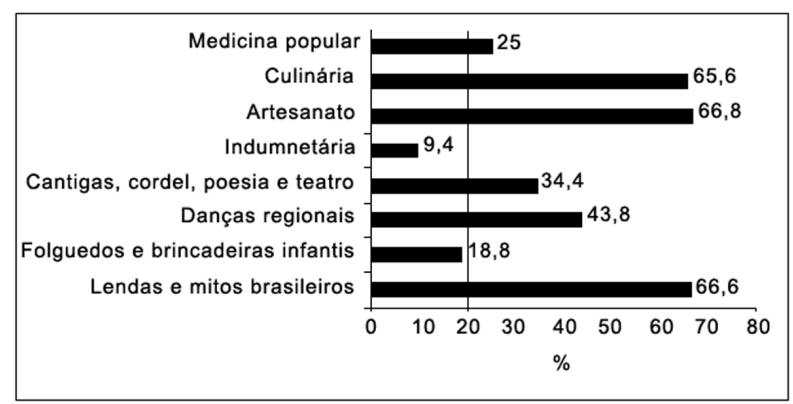

FIGURA 1- Elementos característicos do folclore capixaba segundo os professores

A Figura 1 permite visualizar informações acerca dos elementos característicos relacionados ao folclore capixaba pela grandeza de sua predominância na opinião dos professores. Temos então que $66,8 \%$ indicaram o Artesanato como uma das principais características predominantes no folclore capixaba, 66,6\% indicaram Lendas e mitos brasileiros, $65,6 \%$ optaram pela Culinária, $43,8 \%$ pelas Danças Regionais; 34,4\% pelas Cantigas, cordel, poesia e teatro, 25\% Medicina popular, 18,8\% por Folguedos e brincadeiras infantis; e apenas 9,4\% indicaram a Indumentária.

Neves (1978), um dos maiores estudiosos do folclore capixaba, caracteriza-o como um variado e opulento acervo de tradições populares, recebidos e adaptados dos portugueses, negros, indí- 
genas e demais imigrantes e/ou migrantes que para o Espírito Santo vieram trazendo consigo sua cultura e acomodando-a ao ambiente social local. É, portanto, um conjunto de elementos culturais abrangentes que remonta a tradições de povos e regiões diversas, de contínua transformação, sendo por isso atual.

A cultura folclórica é adquirida de maneira espontânea, sem obrigatoriedade de horário ou dia. Em folclore aprendemos por necessidade, por vontade de participar de algo, porque percebemos que somos parte do grupo, da sociedade em que vivemos (GUIMARÃES, 2002).

Os elementos popularidade e tradicionalidade estão relacionados, respectivamente à aceitação coletiva e à continuidade no tempo. A cultura popular não é nem poderia ser estática, visto que é capaz de assimilar novos conteúdos, e não sendo teórica, existe por uma prática constante. Sua funcionalidade exige essa prática e, assim, ela está sempre em processo de atualização.

De acordo com Hobsbawm (1997), as tradições são dinâmicas, estão sempre em atualização sendo (re)inventadas. As tradições são um conjunto de práticas, normalmente reguladas por regras tácitas ou abertamente aceitas, de natureza ritual e simbólica que visam inculcar certos valores e normas de comportamento através da repetição, o que implica uma continuidade em relação ao passado. O seu principal objetivo e característica é a invariabilidade.

As tradições são inventadas, como no caso de instituições políticas, movimentos ideológicos e grupos, inclusive o nacionalismo, sem antecessores, que tornaram necessária a invenção de uma continuidade histórica, por exemplo, através de um passado baseado em lendas ou simplesmente inventado. De acordo com o autor, as tradições modernas podem se classificar em três categorias superpostas:

a) aquelas que simbolizam a coesão social ou as condições sociais de admissão de um grupo ou de comunidades reais ou artificiais; b)aquelas que estabelecem ou legitimam instituições, status ou relação de autoridade, e c) aquelas cujo propósito inicial é a socialização, a inclusão de idéias, sistemas de valores e padrões de comportamento (HOBSBAWM, 1997, P. 17).

Para nossas análises, torna-se interessante à observação da primeira categoria (tradições que simbolizam a coesão social ou as condições de admissão a grupos), na qual podemos inserir o estudo de alguns fatos folclóricos que são elevados a categorias símbolo da nossa identidade social, como por exemplo, o caso da panela de barro e de dois pratos nela confeccionados, a torta e moqueca capixaba.

Nas representações dos professores acerca do folclore capixaba, vários elementos foram destacados, como o artesanato, mitologia e lendas, culinária típica, cantigas, cordel, medicina popular, brincadeiras, etc. Mas quando questionados a indicar quais elementos representavam a vitalidade do folclore local, foram enfáticos os destaques feitos ao artesanato (panela de barro) e à culinária (torta e moqueca) típica. O mesmo destaque foi observado quando os sujeitos se expressaram sobre quais seriam os elementos constitutivos da identidade capixaba.

TABELA 3

Onde tem sido mais expressiva a vitalidade do folclore segundo os professores

$\begin{array}{lr}\text { RESPOSTAS } & \% \\ \text { Comunicação popular } & 21,7 \\ \text { Tradições locais } & 24,8 \\ \text { Atividades artesanais e culinárias } & 78\end{array}$

* A soma total das porcentagens ultrapassa $100 \%$, pois foram consideradas respostas múltiplas.

Quando questionados sobre os espaços onde têm sido mais expressiva a vitalidade do folclore na atualidade, Tabela 3, podemos observar que a maioria (78\%) escolheu a alternativa relacionada às atividades artesanais e culinárias. Comparando tal escolha com a anterior (Tabela 2), verificamos que ambas apresentaram pontos de vista confluentes, a vitalidade do folclore capixaba é condicionada à sua reprodução na cultura de massa ${ }^{2}$ (shows, feiras, restaurantes, etc.).

Podemos acreditar que alguns elementos folclóricos foram transformados em símbolos identitários num passado recente, por instituições governamentais e empresas turísticas, com o objetivo de criar uma imagem que definisse o estado frente às outras unidades da federação, indicando seus pontos atrativos, riquezas naturais, produtos e serviços, como observamos na atualidade, por exemplo, o projeto da Rota do Sol e da Moqueca ${ }^{3}$, organizado pelas prefeituras de Vitória, Serra, Vila Velha e Guarapari, com o apoio do ES Convention \& Visitors Bureau e da EMBRATUR. O projeto tem como objetivo vender o turismo capixaba em nível nacional e internacional, oferecendo roteiros praianos associados à culinária local. Empreendimentos como este, abarcam uma série de características culturais que, destacadas pela mídia, acabam por formar um imaginário sobre o que corresponderia a uma identidade local. 
A partir dessa observação ressaltamos mais um ponto a ser discutido, referente à difusão do folclore. Quando analisamos as respostas dos professores sobre onde tem sido mais concentrada sua reprodução e (re)adaptação a maioria indicou que ela se dá na cultura de massa, transformando as manifestações folclóricas ou seus objetos em produtos vendáveis.

TABELA 4

Onde têm sido mais concentradas a reprodução e (re)adaptação do folclore segundo os professores

RESPOSTAS

Na cultura de massa, transformadas em

objetos vendáveis

Na cultura erudita

Na cultura espontânea, sem necessidade de

recursos da mídia para divulgação

Não responderam

* A soma total das porcentagens ultrapassa 100\%, pois foram consideradas respostas múltiplas.

Como é possível observar na Tabela 4, $(65,6 \%)$ dos entrevistados acreditam que a reprodução e (re)adaptação do folclore se dá na cultura de massa, onde são transformados em objetos vendáveis. Tal resultado toma contornos mais interessantes se observarmos que quando questionados sobre as características do folclore (Tabela 1), apenas $6,3 \%$ professores o associaram à cultura de massa.

Esta incongruência se resolve quando verificamos que a justificativa, para a escolha da afirmativa de que a reprodução e (re)adaptação do folclore se dá na cultura de massa, argumenta em linhas gerais, sobre a impossibilidade de fugir às investidas da mídia e, portanto, o folclore acaba explorado por esta. Porém, ainda assim, o que prevalece é a espontaneidade restrita à região onde se originou determinado fato folclórico.

As outras respostas sobre essa questão (reprodução do folclore), concentram-se na: cultura espontânea, sem necessidade de recursos da mídia para divulgação $(43,6 \%)$ e na cultura erudita ${ }^{1}$ (nos círculos intelectuais, universidades e instituições de pesquisa), com $18,6 \%$ das escolhas.

Coelho Netto (1987) explica que a criação de uma cultura de massa antecede o desenvolvimento de meios de comunicação de massa. Essa cultura, portanto, surgiu e se desenvolveu com os primeiros jornais, romances de folhetins e posteriormente o rádio, a T.V. e a comunicação virtual. A partir do século XIX, com o fenômeno da industrialização, a cultura massificada se incorpora como produto e se expande sem fronteiras junto à indústria fabril:
É a industrialização, através das alterações que cria no modo-de-produção e na forma do trabalho humano, que determina um tipo particular de indústria (a cultural) e de cultura (a de massa), implantado numa e noutra os mesmos princípios em vigor na produção econômica em geral: o uso crescente da máquina e a submissão do ritmo humano de trabalho ao ritmo da máquina; a exploração do trabalhador; a divisão do trabalho. Estes são alguns dos traços marcantes da sociedade capitalista liberal, onde é nítida a oposição de classes e em cujo interior começa a surgir a cultura de massa (COELHO NETTO, 1987, p. 10).

De acordo com Guareschi (1999), os meios de comunicação de massa legitimam o consumismo e constroem a infra-estrutura de dependência e ajuda às corporações capitalistas (principalmente multinacionais) na venda de seus produtos. A sofisticada tecnologia de comunicações usa técnicas de persuasão, manipulação e penetração cultural, introduzindo novas idéias, gostos e crenças nas sociedades.

$\mathrm{O}$ autor ressalta que, em toda a parte, a cultura local está enfrentando o afogamento que os excedentes dos meios de comunicação de massa, produzidos com finalidade ideológica e comercial, estão causando. E como exemplo dessa problemática, nos cita o caso da T.V., cuja programação está montada para atender aos interesses dos patrocinadores que financiam a programação, "[...] ignorando-se as disparidades, em níveis econômicos, entre os estados e suas necessidades, conseqüentemente, diferentes no campo das comunicações" (GUARESCHI, 1999, p. 76).

Bosi (1996), complementando o debate, acredita que com o avanço da industrialização começou uma nova era para a cultura popular: perdendo suas características folclóricas, organizada por empresários da indústria do lazer, sendo fortemente estruturada em função de um certo públicomassa, criando assim, distinções sócio-econômicas:

A cultura de massas, diferentemente do folclore, não tem raízes na vivência cotidiana do homem da rua. Ela produz modas (rock and roll, twist), mas não foi capaz de criar nada que se assemelhasse ao jazz do negro americano: jazz que a cultura erudita admira enquanto rejeita aquelas modas massivas (BOSI, 1996, p. 77).

Entretanto, segundo Guimarães, a cultura 
popular, mesmo não necessitando de meios (mídias) sofisticados para sua divulgação, visto que faz parte do nosso cotidiano, pode utilizá-los. Os fatos folclóricos podem também sofrer influência tanto da cultura erudita, quanto da cultura de massa, assim como influenciá-las. A constante troca de influências entre os três parâmetros da cultura caracteriza o processo da dinâmica cultural: "[...] a cultura informal está presente na vida de todos nós, independentemente de nossa condição econômica, de nosso status sociocultural. Todos nós somos portadores do folclore!" (BOSI, 1996, p. 5).

O processo de difusão e circularidade do folclore também ocorrem, segundo os professores, na escola, através do desenvolvimento de atividades de pesquisa (pelos alunos), e da prática de projetos interdisciplinares pelos docentes, que enriquecem o processo de ensino-aprendizagem.

TABELA 5

Formas de difusão do folclore na escola

$\begin{array}{lr}\text { RESPOSTAS } & \% \\ \text { Através do incremento da } & 75 \\ \text { interdisciplinaridade } & \\ \text { Incorporado a alguma disciplina que } & 15,7 \\ \text { tematize a questão cultural } & 9,3 \\ \text { Transformado em disciplina específica } & 100 \\ \text { Total } & \end{array}$

Como é possível observar na Tabela 5, (75\%) dos entrevistados consideram o incremento da interdisciplinaridade como forma ideal de se disseminar a importância do folclore dentro da escola, outros $15,7 \%$ preferem que o folclore seja incorporado a alguma disciplina que tematize a questão cultural, e, 9,3\% acreditam que seria ideal a criação de uma disciplina específica sobre o folclore.

O estudo da cultura popular tem muito a contribuir para a democratização dos conteúdos apresentados pelo ensino formal, criando vários canais de ligação entre professor, material didático e aluno. A prática da interdisciplinaridade (NOGUEIRA, 2001) - trabalho conjunto de duas ou mais disciplinas em busca de objetivos comuns -, já tem possibilitado essa experiência, pois a maioria dos professores pesquisados afirmaram que desenvolvem projetos nesse sentido, onde se destacam os temas: música, dança e festas, artesanato, estórias e lendas, e culinária. Quanto às disciplinas que mais se enquadram nesse trabalho, são elas: Linguagem oral e escrita, Geografia, História e Educação Artística. Possivelmente a ocorrência de tais disciplinas se deve a uma maior aproximação destas com os temas da área histórico-cultural, fato que verificamos nos materiais didáticos e nas atividades desenvolvidas por seus professores.

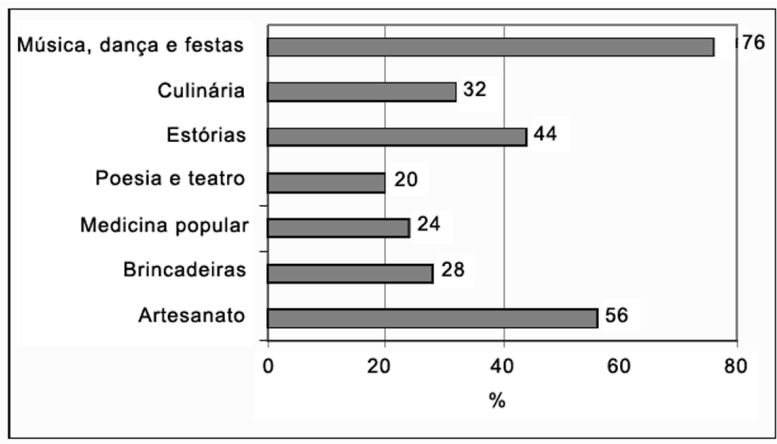

FIGURA 2- Atividades desenvolvidas na escola que utilizam o folclore

Na Figura 2 podemos verificar quais são os elementos folclóricos utilizados nas atividades desenvolvidas na escola: $76 \%$ dos professores utilizam-se das músicas, danças e festas; $56 \%$ artesanatos; $44 \%$ estórias; $32 \%$ culinária; $28 \%$ brincadeiras; $24 \%$ medicina popular, e $20 \%$ utilizam a poesia e a representação teatral.

Consideramos, pelo que foi dito, que a cultura popular constitui-se em um instrumento fecundo para a compreensão da vida social. O folclore, entendido como "[...] todos elementos culturais que constituem soluções usuais e costumeiramente admitidas e esperadas dos membros de uma sociedade transmitida de geração em geração [...] (FERNANDES, 1978), pode agir como elemento de fomento à constituição de uma identidade social ampla (devido à sua circularidade), que una os indivíduos a um grupo ou grupos sociais.

A maioria dos sujeitos pesquisados admitiu a existência de uma identidade capixaba pautada num compartilhar cultural, que se constitui, a partir da difusão e valorização do folclore, da transferência de geração em geração das tradições em geral, da vida cotidiana e da comunicação informal, da divulgação da história e geografia regionais e através dos meios de comunicação de massa.

TABELA 6

Como a identidade capixaba se constrói de acordo com os professores

$\begin{array}{lr}\text { RESPOSTAS } & \% \\ \text { Divulgação/valorização do folclore } & 52,7 \\ \text { Divulgação/valorização da geografia e da história locais } & 15,5 \\ \text { Através dos meios de comunicação } & 15,5 \\ \text { Tradição/ transmissão de geração em geração } & 24,8 \\ \text { Resistência cultural } & 3,1 \\ \text { Não responderam } & 18,6\end{array}$

* A soma total das porcentagens ultrapassa $100 \%$, pois foram consideradas respostas múltiplas. 
A Tabela 6 nos apresenta dados que possibilitam a seguinte interpretação sobre a construção da identidade capixaba: $52,7 \%$ dos professores acreditam que a divulgação e a valorização do folclore de uma forma geral (pela escola, governo, associações culturais, nas relações interindividuais do dia-a-dia, etc.) é um dos seus principais subsídios; $24,8 \%$ responderam que as tradições, sobretudo as familiares, transmitidas de geração em geração são cruciais. Os outros professores resaltaram também: a divulgação da geografia e da história locais $(15,5 \%)$; a utilização dos meios de comunicação $(15,5 \%)$ e a resistência cultural $(3,1 \%)$. Já $18,6 \%$ dos entrevistados não responderam a questão, desconhecendo talvez os processos de construção de identidades.

Quanto às representações da identidade capixaba propriamente ditas, seus elementos constitutivos, obtivemos uma diversidade de respostas, que variam, da combinação de elementos folclóricos (tais como: manifestações artístico-culturais, culinárias e artesanato típico), até referências à história local e ao meio-geográfico, entre outros. Vejamos as representações sociais de $75,2 \%$ dos professores que responderam a respeito de quais seriam os principais elementos constitutivos da identidade capixaba:

TABELA 7

Os principais elementos que constituem a identidade capixaba segundo os professores

$\begin{array}{lr}\text { OPÇÕES DE RESPOSTA } & \% \\ \text { Manifestações artístico-culturais (em geral) } & 34,1 \\ \text { Tradição oral } & 12,4 \\ \text { Culinária típica } & 34,1 \\ \text { Elementos da cultura afro-brasileira } & 3,1 \\ \text { O meio geográfico } & 12,4 \\ \text { Artesanato típico } & 24,8 \\ \text { Religiosidade } & 12,4 \\ \text { A história local } & 15,5 \\ \text { Não responderam } & 24,8\end{array}$

* A soma total das porcentagens ultrapassa 100\%, pois foram consideradas respostas múltiplas.

De acordo com os dados apresentados na Tabela 7, verificamos, que segundo os professores, a identidade capixaba é formada pelos seguintes elementos: manifestações artístico-culturais em geral, 34,1\% (foram citadas festas tradicionais, música e medicina popular, etc.); culinária típica $34,1 \%$ (destaques: torta e moqueca capixaba); artesanato típico $24,8 \%$ (principalmente as panelas de barro, artesanato de conchas, cerâmica, etc.); a história local 15,5\%; a tradição oral 12,4\% (receitas, costumes, simpatias, etc.); o meio geográfico $12,4 \%$ (as praias, o mangue, as montanhas); a religiosidade $12,4 \%$ (templos históricos, festas religiosas); e alguns elementos da cultura afro- brasileira 3,1\% (música e dança, como o congo). Quanto aos $24,8 \%$ dos professores que não responderam a questão, podemos supor ao menos duas explicações: ou não concordaram com a idéia de uma identidade capixaba, ou concordando com tal idéia, não identificaram os seus elementos constitutivos.

De acordo com Moscovici (1984), as Representações Sociais podem ser entendidas como um conhecimento do senso comum, socialmente construído e socialmente partilhado, que se vê nas mentes das pessoas e na mídia, nos bares, nas esquinas, nos comentários das rádios e TVs. Podese dizer que as R.S. são realidades sociais e culturais, e não meras produções simbólicas de indivíduos isolados. Elas existem tanto na cultura como nas mentes das pessoas, são coletivamente sentidas e percebidas. Expressam e estruturam tanto a identidade como as condições sociais dos atores que as produzem e as transformam.

Portanto, as R.S. apresentam-se como fonte para a compreensão dos mecanismos que compõem o processo de constituição da identidade social dos indivíduos (definida por Tajfel como o conhecimento que o sujeito tem, de pertencimento a determinados grupos sociais e o valor emocional atribuído a essa pertença), visto que os grupos sociais recorrem constantemente ao uso de representações tanto para a promoção de uma consciência comum no âmbito interno (intra-grupo), quanto para a defesa de interesses próprios no contexto externo (inter-grupo).

As representações sociais dos professores sobre o folclore capixaba, em todas as questões propostas no instrumento de coleta de dados (desde suas características, como: aceitação coletiva, tradicionalidade, dinamicidade e funcionalidade; até as referências sobre sua utilização cotidiana e na escola; e sua função homogeneizadora na constituição de uma identidade local), nos parecem positivas, o que pode ser interpretado como uma forma de valorização das características do grupo social (capixaba), em contraposição aos de fora (cariocas, baianos, paulistas, etc.).

Partilhar a identidade capixaba, na visão dos sujeitos seria, portanto, participar de alguma forma das manifestações artístico-culturais (como as congadas, as puxadas de mastro, procissões religiosas, etc.), mesmo que de fora, como curioso ou simples espectador; perceber o valor da história (analisando nossos problemas sócio-econômicos objetivando solucioná-los e valorizando nossas conquistas), e da geografia (sentindo-se em casa, num passeio por nossas praias e montanhas); 
desfrutar das delícias de nossa culinária típica (uma bela moqueca cozida numa panela de barro confeccionada pelas tradicionais paneleiras); ir a feirinhas de bairro e comprar um artesanato manufaturado pelo artesão local; escutar dos mais idosos, receitas, aconselhamentos, superstições, idéias que percorrem gerações, que possam nos ajudar a resolver problemas do cotidiano; ou seja, para se identificar como capixaba, basta querer, basta se sentir capixaba.

Desta forma, preconizando o intercâmbio dialético entre representações e identidade social, como proposto por Breakwell (1993), verificamos no presente estudo, que a representação social pode decorrer tanto de uma afiliação grupal quanto a adoção de uma representação pode vir a definir uma afiliação a um grupo social, ou seja, o conhecimento do senso comum, socialmente construído e socialmente partilhado, os modos de pensar e agir dos sujeitos podem se pautar numa afiliação desses sujeitos a um grupo, como também, as R.S. podem definir uma afiliação, constituindo o conhecimento que o sujeito tem, de pertencimento a determinados grupos sociais e o valor emocional atribuído a essa pertença.

Tal intercâmbio fica demonstrado, quando observamos a crença dos sujeitos numa identidade capixaba pautada num conjunto de elementos culturais compartilhado pelos grupos sociais locais, que se constrói no cotidiano e estrutura as condições sociais dos atores que as produzem e as transformam.

O debate sobre a identidade capixaba nunca esteve tão vivo e sua divulgação tão intensificada na mídia em geral. Observamos que, com o desenvolvimento político-econômico do estado, articularam-se elementos (a instalação de grandes indústrias e a ampliação dos portos, o processo migratório, a consolidação de uma elite política e empresarial local), que possibilitaram a criação de uma imagem que definisse o Espírito Santo, suas peculiaridades empreendedoras, e sua população, uma identidade característica, que nos diferenciassem dos outros, dos nossos vizinhos, principalmente dos estados do sudeste.

Desta forma o Espírito Santo pode participar do imaginário nacional, simbolizado de alguma forma, (pela panela de barro e a moqueca capixaba, pelo batuque do congo, pelo marlim-azul do nosso litoral, pela religiosidade presente nas festas populares, pelas montanhas de clima europeu ou pela receptividade dos seus habitantes), em comparação com o Rio, (do Pão de Açúcar e do Cristo, do samba e da malandragem), com São Paulo (da Avenida Paulista, com seu poderio econômico e sotaque carregado nos erres), ou Minas, (com suas riquezas barrocas e seu pão de queijo).

Este processo de constituição de identidades está em constante gestão, tanto dentro, quanto fora do estado, numa associação de elementos, valorativos e também depreciativos, que nos definem como pertencentes a determinado grupo ou grupos sociais, nos caracterizando ou não como capixabas. Afinal, com o avanço do processo de globalização e todas as suas conseqüências transformadoras da realidade social, para ser capixaba não basta, apenas, nascer no Espírito Santo, faz-se necessário o partilhar da vida cotidiana e dos sentidos locais.

\section{NOTAS}

${ }^{1}$ A cultura popular ou espontânea, não necessita de meios (mídias) sofisticadas para sua divulgação, mesmo podendo recorrer a eles. A cultura espontânea faz parte do nosso dia-a-dia de maneira tal, que se torna perene, duradoura, comum na vida de todos nós; tão comum que, muitas vezes, passa despercebida (GUIMARÃES, 2002, p.4).

${ }^{2}$ A cultura de massa surge com o desenvolvimento de múltiplos fenômenos sociais, tais como a urbanização, a industrialização e o desenvolvimento econômico e social. Rádio, televisão, cinema, jornal, Internet, etc. são seus principais veículos. A informação produzida é precária, porque dura um curto espaço de tempo, o que interessa é a novidade (GUIMARÃES, 2002, p. 4).

${ }^{3}$ PROJETO ROTA DO SOL E DA MOQUECA. Disponível em: www.rotadosoledamoqueca.com.br. Acesso em: 15 mai. 2003.)

${ }^{4}$ A cultura erudita caracteriza-se pela informação sistemática, orientada ideologicamente por determinadas posturas intelectuais. É aprendida e divulgada na escola ou por intermédio de instituições por ela reconhecida como legítimas. É uma cultura perene, duradoura, capaz de perpetuarse no tempo e no espaço, porque cultiva o conhecimento teórico, científico e exercita-se constantemente, a fim de manter suas idéias como verdadeiras (GUIMARÃES, 2002, p. 3).

\section{REFERÊNCIAS}

BARDIN, L. Análise de conteúdo. Lisboa: Ed. 70/ Persona, 1979.

BOSI, E. Cultura de massa e cultura popular: leituras operárias. 9.ed. Petrópolis: Vozes, 1996.

BREAKWELL, G.M. Integrating paradigms, methodological implications. In: BREAKWELL, 
Garcia, A.L. "A identidade capixaba em questão: uma análise psicossocial"

G.M. \& CANTER, D.V. (Eds.). Empirical approaches to social representations. London: Oxford University Press, 1993, p. 180-201.

BURITY, J.A. (Org.). Cultura e identidade: perspectivas interdisciplinares. Rio de Janeiro: DP\&A, 2002.

COELHO NETTO, J. T. O que é industria cultural. 9. ed. São Paulo: Brasiliense, 1987.

FERNANDES, F. O folclore em questão. São Paulo: Hucitec, 1978.

GUARESCHI, P. A. Comunicação e poder: a presença e o papel dos meios de comunicação de massa estrangeiros na América Latina. 12.ed. Petrópolis: Vozes, 1999.

GUIMARÃES, J. G. M. Repensando o folclore. São Paulo: Manole, 2002.

HOBSBAWM, E. A invenção das tradições. In: HOBSBAWM, E. e RANGER, T. A invenção das tradições. 2. ed. São Paulo: Paz e Terra, 1997, p. 9-23.

MOSCOVICI, S. The phenomenon of social representations. In: FARR, R.M. \& MOSCOVICI, S. (Eds.). Social representations. Cambridge: Cambridge University Press, 1984, p. 3-69.

MOSCOVICI, S. A representação social da psicanálise. Rio de Janeiro: Zahar, 1978.

NEVES, G. S. Folclore brasileiro - ES. Rio de Janeiro: Funarte, 1978.

NOGUEIRA, R. N. Interdisciplinaridade aplicada. São Paulo: Érica, 2001.

TAJFEL, H. Grupos Humanos e categorias sociais. v. 1. Lisboa: Livros Horizonte, 1982.

TAJFEL, H. Grupos Humanos e categorias sociais. v. 2. Lisboa: Livros Horizonte, 1983.

Aldemir Luiz Garcia é Mestre em Psicologia pela UFES, docente no Centro de Ensino Superior Anísio Teixeira (CESAT) e Centro Universitário de Vilha Velha (UVV). O endereço eletrônico do autor é: aldemir.garcia@terra.com.br 